\title{
ON THE CAUCHY-RASSIAS INEQUALITY AND LINEAR $n$-INNER PRODUCT PRESERVING MAPPINGS
}

\author{
Choonkil BaAk, Hahng-Yun Chu and Mohammad Sal Moslehian
}

Abstract. We prove the Cauchy-Rassias stability of linear $n$-inner product preserving mappings in $n$-inner product Banach spaces. We apply the Cauchy-Rassias inequality that plays an influencial role in the subject of functional equations. The inequality was introduced for the first time by Th. M. Rassias in his paper entitled: On the stability of the linear mapping in Banach spaces, Proc. Amer. Math. Soc. 72, (1978), 297-300.

Mathematics subject classification (2000): 39B52, 46B04, 46B20, 51Kxx.

Key words and phrases: Cauchy-Rassias stability, linear $n$-inner product preserving mapping, $n$-inner product Banach space, Hilbert space.

\section{REFERENCES}

[1] C. Diminnie, S. GÄHLeR AND A. White, 2 -inner product spaces, Demonstratio Math. 6 (1973), $525-536$.

[2] J. ChMIELIŃSKI, On a singular case in the Hyers-Ulam-Rassias stability of the Wigner equation, J. Math. Anal. Appl. 289 (2004), 571-583.

[3] J. CHMIELIŃSKI, Linear mappings approximately preserving orthogonality, J. Math. Anal. Appl. (to appear).

[4] J. ChMieliński, S. Jung, The stability of the Wigner equation on a restricted domain, J. Math. Anal. Appl. 254 (2001), 309-320.

[5] Y. J. Cho, P. C. S. Lin, S. S. Kim And A. Misiak, Theory of 2 -Inner Product Spaces, Nova Science Publ., New York, 2001.

[6] H. GunAWAN, An inner product space that makes a set of vectors orthonormal, J. Austral. Math. Soc. Gaz. 28 (2001), 194-197.

[7] D. H. Hyers, G. IsAC AND Th. M. RASSIAS, Stability of Functional Equations in Several Variables, Birkhauser, Boston, Basel, Berlin, 1998.

[8] D. H. Hyers, TH. M. Rassias, Approximate homomorphisms, Aequationes Mathematicae 44 (1992), $125-153$.

[9] K. JUN, Y. LEE, A generalization of the Hyers-Ulam-Rassias stability of Jensen's equation, J. Math. Anal. Appl. 238 (1999), 305-315.

[10] A. MISIAK, $n$-inner product spaces, Math. Nachr. 140 (1989), 299-319.

[11] C. PARK, On the stability of the linear mapping in Banach modules, J. Math. Anal. Appl. 275 (2002), $711-720$

[12] C. PARK, Linear functional equations in Banach modules over a $C^{*}$-algebra, Acta Appl. Math. 77 (2003), 125-161.

[13] C. PARK, Modified Trif's functional equations in Banach modules over a $C^{*}$-algebra and approximate algebra homomorphisms, J. Math. Anal. Appl. 278 (2003), 93-108.

[14] C. PARK, Lie *-homomorphisms between Lie $C^{*}$-algebras and Lie *-derivations on Lie $C^{*}$-algebras, J. Math. Anal. Appl. 293 (2004), 419-434.

[15] C. PARK, Universal Jensen's equations in Banach modules over a $C^{*}$-algebra and its unitary group, Acta Math. Sinica 20 (2004), 1047-1056. 
[16] C. PARK, Homomorphisms between Lie JC* -algebras and Cauchy-Rassias stability of Lie JC ${ }^{*}$-algebra derivations, J. Lie Theory 15 (2005), 393-414.

[17] C. PARK, Isomorphisms between unital $C^{*}$-algebras, Math. Ineq. Appl. (to appear).

[18] C. PARK, Positive linear operators in $C^{*}$-algebras, Math. Ineq. Appl. (to appear).

[19] C. PARK, Homomorphisms between $C^{*}$-algebras and linear derivations on $C^{*}$-algebras, Math. Ineq. Appl. (to appear).

[20] C. PARK, Homomorphisms between Poisson JC* -algebras, Bull. Braz. Math. Soc. (to appear).

[21] C. PARK, J. HoU, Homomorphisms between $C^{*}$-algebras associated with the Trif functional equation and linear derivations on $C^{*}$-algebras, J. Korean Math. Soc. 41 (2004), 461-477.

[22] A. PRAStaro, TH. M. Rassias, Ulam stability in geometry of PDE's, Nonlinear Functional Analysis and Applications 8 yr 2003, 259-278.

[23] TH. M. RASSIAS, On the stability of the linear mapping in Banach spaces, Proc. Amer. Math. Soc. 72 (1978), 297-300.

[24] TH. M. RASSIAS, The problem of S.M. Ulam for approximately multiplicative mappings, J. Math. Anal. Appl. 246 (2000), 352-378.

[25] TH. M. RAssias, On the stability of functional equations in Banach spaces, J. Math. Anal. Appl. 251 (2000), 264-284.

[26] TH. M. RASSIAS, On the stability of functional equations and a problem of Ulam, Acta Applicandae Mathematicae 62 (2000), 23-130.

[27] TH. M. Rassias, P. ŠEMRL, On the Hyers-Ulam stability of linear mappings, J. Math. Anal. Appl. 173 (1993), 325-338. 